\title{
Qualitative Study of Breastfeeding Support by Public Health Nurses in Japan
}

\author{
Noriko Toyama1, Mineko Muranaka², Kayoko Kurihara', Kiyoko Kamibeppu${ }^{1}$ \\ ${ }^{1}$ Department of Family Nursing, School of Health Sciences and Nursing, Graduate School of Medicine, The University of Tokyo, \\ Tokyo, Japan \\ ${ }^{2}$ Japanese Nursing Association, Tokyo, Japan \\ Email: ntoyama-tky@umin.ac.jp
}

How to cite this paper: Toyama, N., Muranaka, M., Kurihara, K. and Kamibeppu, K. (2017) Qualitative Study of Breastfeeding Support by Public Health Nurses in Japan. Health, 9, 451-458.

https://doi.org/10.4236/health.2017.93032

Received: February 10, 2017

Accepted: March 12, 2017

Published: March 15, 2017

Copyright $\odot 2017$ by authors and Scientific Research Publishing Inc. This work is licensed under the Creative Commons Attribution International License (CC BY 4.0).

http://creativecommons.org/licenses/by/4.0/

\begin{abstract}
This study aimed to explore breastfeeding support by public health nurses (PHNs) working in Japanese municipalities in order to promote a breastfeeding-friendly environment. We interviewed 20 participants including five PHNs, four midwives, four doctors (one obstetrician and three pediatricians), and seven mothers who experienced breastfeeding between June and August 2010 and analyzed the data using content analysis. Collected data were classified into four categories including "collecting information", "assessment", "direct and individual support", and "support for group and community" with 15 subcategories: infant's condition, mother's condition, mother-infant relationship, child rearing environment, mother's state-of-mind, identifying necessary support, psychological support, concrete support, breastfeeding on demand, necessary information, advice to supporters, introducing services, breastfeeding-friendly environment, breastfeeding support groups and cooperation with relevant organization. This study suggested that the PHNs' responsibilities for breastfeeding support should be extended beyond the currently understood scope of their duties. The study demonstrated that PNH needed to create a breastfeeding-friendly environment that included networking with breast care support organizations and peer groups and to promote breastfeeding in public areas including the workplace.
\end{abstract}

\section{Keywords}

Public Health Nurse, Breastfeeding Support, Qualitative Research

\section{Introduction}

\subsection{Breastfeeding Trend}

Breastfeeding has various health benefits for mothers and children [1] [2] [3]; therefore, it is promoted in many countries including Japan. The WHO and UNICEF 
recommend breastfeeding exclusively for the first 6 months after birth in their report, "Global Strategy for Infant and Young Child Feeding" [4]. The Young Child Physical Development Survey of the Ministry of Health, Labour and Welfare of Japan, conducted every ten years since 1960, demonstrated that the breastfeeding rate for 1 to 2 -month-old infants was $70.5 \%$ in 1960 but decreased to $31.7 \%$ in 1970 and had remained low since then [5]. Increasing the breastfeeding rate of 1-month-old infants was a goal of Healthy Family 21, a national campaign for maternal and child health $(\mathrm{MCH})$ begun in 2000 in Japan. In order to share the rationale for breastfeeding with health workers and to support mothers who wish to breastfeed their child, the Ministry of Health, Labour and Welfare published and promoted the Guide for Feeding and Weaning Infants and Young Children in 2007 [6]. As a result, according to the Young Child Nutrition Survey, the breastfeeding rate of 1-month-old infants increased by $51.3 \%$ in 2015 . However, about $78 \%$ of mothers surveyed still expressed some reservations about breastfeeding [7].

\subsection{Breastfeeding Support by Public Health Nurse}

Based on the MCH law enacted in 1965, public health nurses (PHNs) who provide home visits and telephone counseling to support mothers and families play an important role in supporting breastfeeding mothers. To increase the breastfeeding rate, PHNs have launched a breastfeeding initiative including group education for mothers, individual counseling, and organizing peer support groups [6] [8]. On the other hand, research results showed that PHNs did not provide sufficient information about the benefits of breastfeeding [9]. Furthermore, Hiraiwa [10] reported that PHNs unnecessarily advised the use of formula milk. Although the support of PHNs is important for mothers, their assistance is still insufficient in various respects. With the ultimate aim of promoting a breastfeeding-friendly environment, this study explored breastfeeding support provided by public health nurses in Japanese municipalities.

\section{Method}

\subsection{Participants and Data Collection}

We interviewed 20 participants including five PHNs, four midwives, one obstetrician, three pediatricians, and seven mothers who experienced breastfeeding between June and August 2010. PHNs, midwives and medical doctors who had more than 5 years working experience were included in this study. A semi-structured interview was conducted in accordance with the interview guide. The interviews lasted from 50 to 70 minutes.

\subsection{Ethical Approval}

Ethical approval for this study was obtained from the Ethical Review Committee of the Faculty of Medicine, the University of Tokyo (Clearance No. 3035).

\subsection{Information Sought in the Interview}

1) Socio-demographic characteristics: sex, age, work experience as a PHN, MW, 
or doctor, mothers' breastfeeding experience.

2) Breastfeeding support: What kind of breastfeeding support should PHNs provide?

\subsection{Data Analysis}

Qualitative content analysis was used to analyze data [11]. First, we read the interview transcripts and formed assessment categories with corresponding codes. Next, we formed sub categories. To ensure the reliability of the categories, $20 \%$ of the codes were independently reviewed by two researchers, and the rate of agreement was calculated. Then the researchers reviewed these classifications and resolved disagreements through discussion. Finally, all the researchers reviewed the codes and categories to designate each of the categories and sub categories with an appropriate label.

\section{Results}

\subsection{Participants}

The median age of the PHNs, doctors, and midwives was 51, 54, and 55 years old, respectively. The median years of employment experience was 9, 25, and 28 years, respectively. Two doctors were male, and the rest of the participants were female. The median age of mothers who practiced breastfeeding was 41 years. The number of children ranged from one to three. The period of breastfeeding ranged from one month to 50 months. The age of children ranged from 1 to 27 years old (Table 1).

\subsection{Breastfeeding Support by PHNs}

Table 2 shows the categorized results of the content analysis. The rate of agreement for the codes was $83.3 \%$ among PHN, 96.8\% among doctors and midwives, and $90.5 \%$ among mothers. These rates were deemed high enough to ensure reliability [11].

Breastfeeding support by PHNs was classified into four categories and 15 subcategories. The categories were labeled, "collecting information", “assessment”, "direct and individual support", and "support for group and community". Each category consisted of multiple subcategories as described below.

\subsubsection{Collecting Information}

"Collecting information" consisted of four subcategories including "Infant's condition", "Mother's condition", "Mother-infant relationship", and "Child rearing environment".

"Infant's condition" was designed to assess the condition of the individual infant. A participant said, "I measure the weight and watch the movements of infants when they are together with their mother. It is important to observe the general condition of infants, not only numerical values like weight". "Mother's condition" was designed to assess the condition of individual mother. A participant mentioned, "It is important to observe the mental and physical condition of the mother 
Table 1. Socio-demographic characteristics of the participants.

\begin{tabular}{ccccccc}
\hline & & Age & $\begin{array}{c}\text { Work } \\
\text { experience }\end{array}$ & $\begin{array}{c}\text { Number of } \\
\text { children }\end{array}$ & $\begin{array}{c}\text { Age of } \\
\text { children }\end{array}$ & $\begin{array}{c}\text { Total period of } \\
\text { breastfeeding (months) }\end{array}$ \\
\hline & N & $\begin{array}{c}\text { Median } \\
\text { (Range) }\end{array}$ & $\begin{array}{c}\text { Median } \\
(\text { Range })\end{array}$ & $\begin{array}{c}\text { Median } \\
\text { (Range) }\end{array}$ & $\begin{array}{c}\text { Median } \\
\text { (Range) }\end{array}$ & $\begin{array}{c}\text { Median } \\
\text { (Range) }\end{array}$ \\
PHN & 5 & $51(28-61)$ & $9(5.8-20)$ & - & & - \\
$\begin{array}{c}\text { Doctor } \\
\text { Midwife }\end{array}$ & 4 & $54(35-62)$ & $25(5-35)$ & - & & - \\
$\begin{array}{c}\text { Mothers who } \\
\text { experienced } \\
\text { breastfeeding }\end{array}$ & 7 & $41(31-62)$ & - & $1(1-3)$ & $4(1-27)$ & $14(1-50)$ \\
\hline
\end{tabular}

Table 2. Breastfeeding support expected of PHNs $(\mathrm{N}=20)$.

\begin{tabular}{|c|c|c|}
\hline & $<$ Category $>$ & \\
\hline & [Sub-category] & Code \\
\hline 1) & $<$ Collecting Information $>$ & \\
\hline$(1)$ & [Infant's condition] & $\begin{array}{l}\text { Measuring weight; observing movements of infant; not- } \\
\text { ing general condition of infant }\end{array}$ \\
\hline$(2)$ & [Mother's condition] & $\begin{array}{c}\text { Mental condition; physical condition; life style; ideas } \\
\text { about breastfeeding }\end{array}$ \\
\hline$(3)$ & [Mother-infant relationship] & $\begin{array}{l}\text { Position during breastfeeding; latching of infant; } \\
\text { mother's expression }\end{array}$ \\
\hline$(4)$ & [Child rearing environment] & $\begin{array}{l}\text { Relationship with husband, family, and friends; living } \\
\text { environment; socio-economic situation }\end{array}$ \\
\hline 2) & $<$ Assessment $>$ & \\
\hline$(5)$ & [Mother's state-of-mind] & Clarifying mother's troubles \\
\hline$(6)$ & [Identifying necessary support] & $\begin{array}{l}\text { Clarifying degree of independence and understanding; } \\
\text { identifying information and support necessary for } \\
\text { mother and family }\end{array}$ \\
\hline 3) & $<$ Direct and individual support $>$ & \\
\hline$(7)$ & [Psychological support] & $\begin{array}{l}\text { Providing psychological support for mothers such as } \\
\text { approval; listening closely; sympathy; acceptance }\end{array}$ \\
\hline$(8)$ & [Concrete support] & $\begin{array}{l}\text { Providing concrete support when troubled such as } \\
\text { coping with failure to lactate; helping underweight } \\
\text { infants to gain weight }\end{array}$ \\
\hline$(9)$ & [Breastfeeding on demand] & $\begin{array}{l}\text { Helping mothers to breastfeed whenever they or their } \\
\text { infant require it }\end{array}$ \\
\hline$(10)$ & [Necessary information] & $\begin{array}{l}\text { Providing information such as Benefits of breastfeeding; } \\
\text { method of breastfeeding; breast care and promoting } \\
\text { breast milk to the mother and family }\end{array}$ \\
\hline (11) & [Advice to supporters] & $\begin{array}{l}\text { Advice to supporters such as the husband, family, and } \\
\text { friends on providing appropriate mental support to } \\
\text { mothers doing breastfeeding }\end{array}$ \\
\hline (12) & [Introducing services] & $\begin{array}{l}\text { Introducing services such as facilities and home visit } \\
\text { services providing breast care whenever the mother needs } \\
\text { them }\end{array}$ \\
\hline 4) & $\begin{array}{l}<\text { Support for group and } \\
\text { community }>\end{array}$ & \\
\hline$(13)$ & $\begin{array}{l}\text { [Breastfeeding-friendly } \\
\text { environment] }\end{array}$ & $\begin{array}{l}\text { Making a local directory of child care services; } \\
\text { establishing public breastfeeding facilities; encouraging } \\
\text { working mothers to continue breastfeeding; raising } \\
\text { awareness about breastfeeding friendly environments }\end{array}$ \\
\hline (14) & [Breastfeeding support groups] & $\begin{array}{l}\text { Forming a peer group to help mothers experiencing } \\
\text { troubled with breastfeeding and Introducing } \\
\text { breastfeeding support group to mother }\end{array}$ \\
\hline (15) & $\begin{array}{l}\text { [Cooperation with relevant } \\
\text { organization] }\end{array}$ & $\begin{array}{l}\text { Sharing information and cooperating with relevant } \\
\text { medical institutes and midwives }\end{array}$ \\
\hline
\end{tabular}


and to hear her opinions about breastfeeding". "Mother-infant relationship" was designed to assess the relationship between mother and infant when the two are together, rather than individually. A participant emphasized, "It is important to observe the position of both mother and infant during breastfeeding, infant latching and the mother's expression". "Child rearing environment" was designed to assess the child care environment globally. A participant said, "It is important to understand the woman's relationship with her husband, family and friends, the living environment and the couple's socio-economic status when PHN visit the mother's home".

\subsubsection{Assessment}

"Assessment" of breastfeeding support consisted of two subcategories including "mother's state-of-mind" and "identifying necessary support". The former subcategory was designed to clarify the mother's concerns regarding breastfeeding. A participant reported "It is important to clearly understand the mother's state-ofmind and any reasons for her feeling concern". "Identifying necessary support" is a subcategory designed to identify the kind of information or help that mothers and their family require but are lacking. A participant explained, "If the mother experiences difficulty while breastfeeding. The PHN should assess the situation very carefully from different points-of-view rather than giving a facile assessment and advice to the mother".

\subsubsection{Direct and Individual Support}

"Direct and individual support" for breastfeeding consisted of six subcategories including "psychological support", "concrete support", "breastfeeding on demand", "necessary information", "advice to supporters" and "introducing services".

"Psychological support" was designed to assess the importance of the PHN's approval of, attention to, sympathy for, and acceptance of, the mother. A participant reported, "If the mother feels any difficulty while breastfeeding and caring for her child. It is very important for the PHN to listen to and accept the mother's opinions". "Concrete support" was designed to assess the importance of maternal coping with problems such as the inability to lactate and of helping underweight infants to gain weight. "Breastfeeding on demand" assessed the importance of supporting breastfeeding activity whenever either the mother or infant required it. "Necessary information" examined providing information of the benefits and promotion of breastfeeding, the methods used, and breast care to the mother and family. "Advice to supporters" assessed the importance of advising those close to the breastfeeding mother such as the husband, family, and friends on how to support her emotionally and psychologically. A participant mentioned, "It is especially important to recognize the feelings of the grandparents who used artificial milk to feed the infant". "Introducing services" addressed the importance of introducing facilities and home visit services providing breast care whenever the mother needs them.

\subsubsection{Support for Group and Community}

"Support for group and community" for breastfeeding consisted of three subca- 
tegories including "breastfeeding-friendly environment", "breastfeeding support groups", and "cooperation with relevant organizations".

"Breastfeeding-friendly environment" assessed the importance of providing a directory of child care services and establishing breastfeeding rooms in public areas. A participant reported, "It is important to advise working mothers to continue breastfeeding and to raise awareness of the importance of having a breastfeeding-friendly environment". "Breastfeeding-support group" assessed forming a peer group to help mothers experiencing troubled with breastfeeding and introducing breastfeeding support group to mother. "Cooperation with relevant organizations" assessed the importance of information-sharing and cooperation with medical institutions and midwives.

\section{Discussion}

Our research showed that PHNs were expected to play many roles in breastfeeding support. The examples of such roles reported by Hirano [12] were 'direct care' such as counseling and education, "grouping and networking", and "systematizing", including guaranteeing and improving the quality of care. The present study suggested that specifying activities in those categories in the context of breastfeeding would help PHNs work more effectively for the benefit of their community.

"Evidence for the Ten Steps to Successful Breastfeeding [13]", a well-known guideline for breastfeeding support, identifies several very important steps for supporting mothers. However, the manual was written for health care staff in treatment centers and does not address the relevance of community activities and public policy changes. The authors of this present study hoped to address this omission for public health nurses working in municipal health centers and the community.

A previous study in Canada showed that a negative breastfeeding support experience was a significant effect modifier on the relationship between breastfeeding difficulties and postpartum depression [14]. The authors suggested that the quality of breastfeeding support was important not only to promote breastfeeding but also to insure maternal mental health through providing mothers with emotional and psychological support. These findings all indicate that health professionals including public health nurses need to pay closer attention to the quality of support for breastfeeding mothers, their family, and the community.

The Ministry of Health, Labour and Welfare [15] announced that "PHN should clarify living environment and health issues in their community, and implement and assess activities designed to promote health within the community". In this study, PHNs were asked to collect information, analyze problems, and implement breastfeeding support. However, the results of the assessment were not included in the results. Further investigation is necessary to assist PHNs in improving their work efficacy.

\section{Limitations}

This study targeted clinical and public health professionals and mothers and 
therefore did not include feedback from researchers and occupational health nurses. In addition, the results of the assessment of the types of support examined were not included in the results. Further studies targeting a broader demographic are necessary to improve breastfeeding support expected of public health nurses.

\section{Conclusions}

This study examined four categories including "collecting information", "assessment", "direct and individual support" and "support for group and community" for assessing breastfeeding support and 15 subcategories, namely, "infant's condition", "mother's, condition", "mother-infant relationship", "child-rearing environment", "mother's state-of-mind", "identifying necessary support", "psychological support", "concrete support", "breastfeeding on demand", "necessary information", "advice to supporters", "introducing services", "breastfeeding-friendly environment", "breastfeeding support groups" and "cooperation with relevant organization".

This study suggested that the PHNs' responsibilities for breastfeeding support should be extended beyond the currently understood scope of their duties. The study demonstrated that PNH needed to create a breastfeeding-friendly environment that included networking with breast care support organizations and peer groups and to promote breastfeeding in public areas including the workplace.

\section{Acknowledgements}

We are grateful to the PHNs, doctors, midwives, and mothers who took the time to participate in our interview. We would also like to express our gratitude to the faculty and members of the Department of Family Nursing, Graduate School of Medicine/Faculty of Medicine School of Health Science \& Nursing of the University of Tokyo.

\section{Conflict of Interest}

We declare no conflict of interest.

\section{Source of Funding}

This study was funded by Grants-in-Aid for scientific research expenses of the Ministry of Education, Culture, Sports, Science and Technology (Grant Number 2139 0589).

\section{Contributions}

Noriko Toyama: study design, data collection, data input, data analysis, discussion, and finalized the manuscript.

Mineko Muranaka: study design, data collection, discussion, and reviewing of the paper.

Kayoko Kurihara: study design, data analysis, discussion, and reviewing of the 
paper.

Kiyoko Kamibeppu: supervised all the processes involved in this study.

\section{References}

[1] Gartner, L.M., Morton, J., Lawrence, R.A., Naylor, A.J., O’Hare, D., Schanler, R.J. and Eidelman, A.I. (2005) Breastfeeding and the Use of Human Milk. Pediatrics, 115, 496-506. https://doi.org/10.1542/peds.2004-2491

[2] Horta, B.L., Bahl, R., Martinés, J.C. and Victora, C.G. (2007) Evidence on the LongTerm Effects of Breastfeeding: Systematic Reviews and Meta-Analysis. World Health Organization, Geneva. http://whqlibdoc.who.int/publications/2007/9789241595230_eng.pdf

[3] Ip, S., Chung, M., Raman, G., Chew, P., Magula, N., De-Vine, D., Trikalinos, T. and Lau, J. (2007) Breastfeeding and Maternal and Infant Health Outcomes in Developed Countries. Evidence Report-Technology Assessment, 153, 1-186.

[4] WHO (2002) Global Strategy for Infant and Young Child Feeding. WHO, Geneva. http://www.who.int/nutrition/publications/gs_infant_feeding_text_eng.pdf

[5] Mother's and Children's Health and Welfare Association (2008) Maternal and Child Health Statistics of Japan. MCHWA, Tokyo, 131-133.

[6] Ministry of Health, Labour and Welfare (2007) Guide for Feeding and Weaning Infants and Young Children. http://www.mhlw.go.jp/shingi/2007/03/dl/s0314-17.pdf

[7] Ministry of Health, Labour and Welfare (2016) Result of Young Child Nutrition Survey in 2015.

http://www.mhlw.go.jp/file/06-Seisakujouhou-11900000-Koyoukintoujidoukateikyo ku/0000134460.pdf

[8] Ogino, A. and Yamagishi, K. (2008) Breastfeeding Promotion Project. Journal of Public Health Nurse, 64, 996-1001.

[9] Nunohara, K., Hattori, R., Nawa, A., Miyamoto, M., Taniguchi, M., Ryou, M. and Tsubouchi, M. (2009) Research on Breastfeeding Support by Public Health Nurse -Focus on Support Policy, Contents and Difficulty. Bulletin of Gifu College of Nursing, 9, 43-51.

[10] Hiraiwa, M. (2009) Guide for Feeding and Weaning Infants and Young Children and Breastfeeding. Public Health, 73, 539-542.

[11] Funashima, N. (2009) Challenge to Qualitative Research. Igakusyoin, Tokyo, 42-46.

[12] Hirano, K. (2000) Prospective of Public Health Nursing. Research on Public Health, 49, 116-124.

[13] WHO (1998) Evidence for the Ten Steps to Successful Breastfeeding. http://www.who.int/nutrition/publications/evidence_ten_step_eng.pdf

[14] Chaput, K.H., Nettel-Aguirre, A., Musto, R., Adair, C.E. and Tough, S.C. (2016) Breastfeeding Difficulties and Supports and Risk of Postpartum Depression in a Cohort of Women Who Have Given Birth in Calgary: A Prospective Cohort Study. Canadian Medical Association Journal Open, 21, E103-E109. https://www.ncbi.nlm.nih.gov/pmc/articles/PMC4866929/pdf/cmajo.20150009.pdf

[15] Ministry of Health, Labour and Welfare (2013) About Activities of Public Health Nurse at the Community. http://www.nacphn.jp/topics/pdf/2013_shishin.pdf 
Submit or recommend next manuscript to SCIRP and we will provide best service for you:

Accepting pre-submission inquiries through Email, Facebook, LinkedIn, Twitter, etc. A wide selection of journals (inclusive of 9 subjects, more than 200 journals)

Providing 24-hour high-quality service

User-friendly online submission system

Fair and swift peer-review system

Efficient typesetting and proofreading procedure

Display of the result of downloads and visits, as well as the number of cited articles Maximum dissemination of your research work

Submit your manuscript at: http://papersubmission.scirp.org/

Or contact health@scirp.org 